Research Article

\title{
Integration of Indigenous Knowledge into Adult Learning Material Development and the Facilitation Methodology
}

\author{
Yalalem Assefa \\ Department of Adult Education and Community Development, Woldia University, Weldiya, Ethiopia \\ Correspondence should be addressed to Yalalem Assefa; yalalem2012@gmail.com
}

Received 26 June 2021; Accepted 19 July 2021; Published 22 July 2021

Academic Editor: Ehsan Namaziandost

Copyright (c) 2021 Yalalem Assefa. This is an open access article distributed under the Creative Commons Attribution License, which permits unrestricted use, distribution, and reproduction in any medium, provided the original work is properly cited.

Connecting indigenous knowledge systems and practices with adult education programs has priceless value of promoting and transferring indigenous perspectives from generation to generation. Indeed, education is the surest path to ensuring social continuity when it ought to be based on the real-life experiences of learners and what their immediate environment and social realities entail. This demands the development of relevant adult learning materials and the utilization of participatory facilitation methodologies. Considering this in mind, this study was aimed to explore the integration of indigenous knowledge into adult education practices. In doing so, a case-study design was employed. The study sample was composed of eighteen experts, seven adult education literacy center coordinators, and seventy adult learners. Interview and FGD were considered the major datagathering tools. Also, thematic analysis was the center of this study's data analysis. As a result, the finding indicated that even though adult learners have diverse learning experiences, narrow emphasis has been given to the development of learning concepts and objectives in adult learning materials. The application of appropriate facilitation methods through participating experienced learners remains symbolic. To enhance the positive inclusion of indigenous knowledge into adult learning, learning material and its facilitation environment must be conducive and adequately be portraited. Therefore, the objective of this study is to explore the existing practice of indigenous knowledge integration into adult education in North Wollo, from the perspectives of learning material development and utilization of the facilitation methodology.

\section{Introduction}

Increasingly, there has been a global shift toward recognizing and understanding the positive value of indigenous models of education as a legitimate form of education [1]. Scholars in the field conceptualized indigenous knowledge (hereafter, IK) as the cumulative body of strategies, practices, techniques, tools, intellectual resources, explanations, beliefs, and values accumulated over time in a particular locality, without the interference and imposition of external hegemonic forces [2-5]. It has been part of the rich cultural heritage of societies [6]. IK is practical knowledge acquired through long-term observation of nature and experiences that reflect the ideas and experiences of local people for adaptation in a particular ecological setting $[2,4,7]$.

Moreover, Singh and Saha [7] mentioned that "IK is the knowledge that people in a given community have developed over time and continues to develop. It is based on experience, often tested over a long period of use, adapted to local culture and environment, dynamic and changing, and emphasizes minimizing risk rather than maximizing profit" ( $\mathrm{p}: 548)$. Most of the time, IK is developed through the practice of experiential learning by people living in a geographical area of local culture over time driven by the pragmatic, utilitarian, and everyday demands of life $[2,8,9]$. Learning about IK may help students recognize the strong connection formed between humans and nature in the foreground of culture from their context [10].

The sophistication of indigenous people's knowledge and beliefs can be blended by incorporating them into formal and nonformal educational systems [11]. Indeed, education is the surest path to ensuring social continuity when it ought to be based on the real-life experiences of learners and what their immediate environment and social realities entail [12]. 
Therefore, indigenous education starts with the identification and analysis of indigenous people's learning needs and aspirations [13]. People who are well versed in IK and understand their environment intimately are more disposed to be inventors and innovative competitors throughout their life [12]. Therefore, it is imperative to emphasize that education for indigenous people must be culturally and linguistically appropriate; otherwise, it may reinforce and perpetuate their marginalization [11]. This requires transformational advocacy in the context of IK aimed at bringing change in adult education (hereafter, $\mathrm{AE}$ ), curriculum, learning materials, and instructional or facilitation strategies [5].

Ethiopia is the only sub-Saharan country possessing an ancient written culture with its alphabet and owns a 1,700year expressed indigenous and traditional knowledge creation system that is embedded in their elite education linked to the Orthodox Church [14]. Beforehand, many studies have been conducted in Ethiopia focusing on IK and AE practice. For instance, many researchers conducted IK-related studies with special emphasis on exploring indigenous educational systems and practices [2, 14-17]. On the other hand, other researchers [18-26] investigated the current practice of $\mathrm{AE}$ and literacy across the context of policy, personnel, learners' participation, governments, and other stakeholders' role in the program. As far as researcher knowledge is concerned, none of the abovementioned studies addressed the inclusion of IK into AE provision, particularly the integration of learning materials and facilitation strategies across learners' contexts. As a result, the researcher believes that enough emphasis is not given to IK and its integration.

The researcher believed that the integration of IK into education demands the reorganization of indigenous frameworks and methodologies which give more attention to learners' history, cultural beliefs, and philosophical views. It, in turn, brings inclusive education with relevant and responsive learning materials and facilitation methods that take the indigenous know-how of local people into account. However, there are three main rationales of the researcher conducting this study. These are (1) when the researchers read many studies conducted on $\mathrm{IK}$, its integration into community-based AE programs was not fully studied and critically addressed. (2) When the researcher discussed with North Wollo (hereafter, NW) AE coordinators in the northeast part of Ethiopia, the achievement was found at an unsatisfactory level that could be explained by different reasons. Therefore, ahead of time, the researchers internalized the aboveidentified problems and initiated to study the integration of IK into AE programs across learning material and facilitation methodology development. With this in mind, therefore, this study tried to address the following two basic research questions:

(i) How does the adult learning material development process consider adult learners' IK systems and practice?

(ii) How has the utilization of the $\mathrm{AE}$ facilitation methodology been functional to scrutinize the relevance and responsiveness of learners' IK to their learning?

\section{Theoretical Framework}

The theoretical framework of the integration of IK into AE is built up with relevant literature from AE learning, material development, and facilitation methodology perspectives. In due course, a sound understanding of how IK systems and practices evolve and how and by whom these are integrated into $\mathrm{AE}$ allows the researcher to describe the necessary conditions across adult learners' local contexts. Indigenous education can generally be demarcated as a form of learning in which knowledge, skills, and attitudes of the community were passed from elders to the child, using oral instructions and practical activities such as watching, participating, and executing what they learned [1]. For indigenous people, AE is also about perpetuating cultural and linguistic practices, reclaiming power over their own lives and destiny, and progressing towards self-determining pathways [13]. Therefore, the inclusion of IK systems and practices into AE learning materials and facilitation is critical and holds the ability to set the stage for advancement in all fields $[12,26]$.

Education and its manifestations in learning materials are by definition a realm of decision making about what and how should the planned learning contents and experiences intend to provide for learners $[27,28]$. The primary aim of education in the curriculum tradition is to create opportunities for learning that help teachers to start a learning process and master a professional practice, where students must achieve predefined outcomes [29, 30]. The first step in building an issue-based and action-oriented adult learning material is the selection of appropriate learning content, experience, and organization into a coherent and theoretically justifiable program [31]. A good learning material, therefore, is a course that pays attention to the needs of learners in the learning environment and receives community support $[29,30]$.

IK and education can build and nurture intercultural and interpersonal respect, responsibilities, and relationships in a holistic manner [32]. Furthermore, other scholars such as Hodson [31] and Mawere [33] suggested three issues that need to be targeted when developing IK-based adult learning materials. These are (1) promotes and enhances innovative thinking and constructivism in learners through real-world problem solving and not focused on the steady accumulation of knowledge; (2) fosters critique and intellectual independence rather than conformity and compliance which helps different cultures/societies to share their knowledge; and (3) promotes the cultivation of interdependence and potential for community building is needed for their good and that of the society of which they are part. Integrating learners' IK in the curriculum makes education relevant to their daily life, which commonly involves the teaching of culturally relevant circumstances [2]. Murillo [28] also suggested three general principles for decision making in IK learning materials and facilitation matters. These principles are flexibility (unrigid prescription of predefined strategies and methods to teach), prioritization (prescribed curricula 
should be adjusted to prioritize the most important cores of contents and skills to present to students at their present level), and integration (ensure that each is treated with integrity with the dignity of content on its own and to a network of other related content).

More than simple indicators of best practice and an epistemological shift that facilitates learning for all learners, a holistic framework is needed for designing a universal learning system [34]. As to them, the application of this epistemological shift helps to address significant practical and social justice concerns. Indigenous education specifically focuses on teaching based on IK models, methods, and content within formal or nonformal educational systems [1]. Similarly, IK-based teaching-learning depends on the integration of knowledge, experience, and skill [35]. This demands the selection of appropriate indigenization pedagogical approaches, teaching-learning methods, and models, which are culturally approachable or cultural-based education that is important to sustainability $[2,10]$.

One of the most significant reasons for intertwining indigenous perspectives within adult learning and pedagogy is to increase indigenous representation in the profession [32]. Hence, the direction and quality of integrating IK into the $\mathrm{AE}$ require investment in professional development and selection of appropriate knowledge-building instructional tools $[26,36]$. If the content (knowledge) is not available in the usual forms and locations (for example, libraries, resource materials, and textbooks), then learning material development in any educational setting requires different professional aptitudes and capabilities [3]. This also calls for reorganizing the development of professionals and practitioners within the learners' cultural context that will provide new teaching, learning, research, and community service $[23,37]$.

Indigenous-based AE facilitation practices are not only the process of interaction between facilitators and learners but also affected by pressures from their social environment which may result in adjusting their standards for types of learners [26]. Teaching indigenous perspectives in AE requires a range of capabilities, dispositions, and knowledge that are often underappreciated, including cross-cultural facilitation skills and indigenous content-specific knowledge $[26,32]$. As to the work of Austin and Hickey [3], facilitators must demonstrate the characteristics of both hermeneuts (structure, work, and teaching around an effort to help students and other individuals to make sense of the world around them) and epistemologists (seek to expose how accepted knowledge came to be validated). Through direct engagement with indigenous perspectives, adult educators and learners can evolve from cognitive understanding and sympathy to empathy and unified consciousness. As a result, IK systems can expose possibilities for contestation, transformation, and reconciliation within one's self and beyond the scope of education or practice [32].

Perceptual sensitivity and knowledgeable action are critical for the development of practical well-grounded methods capable of supporting the full spectrum of facilitation for learning [35]. Thus, educators in all forms and sectors of community-based education, from formal settings to nonformal settings, need to change their ways of thinking about the broader aspects of IK-based learning [34]. Through continuous professional development and learning activities, facilitators can learn to plan, define learning objectives, deliver instruction, test, and assess learners' learning, as well as to conduct local curriculum evaluation [30].

When indigenous learners contribute something to their communities, learning facilitators may need to recognize that patterns of thinking, metaphors versus theory for once ptyalizing, may be very different [38]. By following the wellestablished, but seldom utilized, principles of universal learning design in [34]; adult educators can reimagine the way learning occurs and how to assess it. Learners also need different methods to present what knowledge they have acquired through expressing in written words, visual, oral, or graphical techniques [34].

\section{Methods}

This study is targeted at the NW administrative zone, found in the northeast part of Ethiopia. During conducting the study, a qualitative research approach was employed $[39,40]$. Since the concentration of this inquiry focused on establishing an in-depth investigation of IK systems and practices, integration into $\mathrm{AE}$ program provision, a case study research design, particularly a collective instrumental case study pioneered by Creswell [41], was employed. In this design, two cases such as adult learning materials and application of a facilitation methodology were considered to scrutinize in-depth integration of IK into AE provisions. The borderline (conceptual context) of these cases is well defined concerning the practical existence defined by study participants' roles and responsibilities such as AE coordinators, experts, and IK owners of adult learners.

The sample participants were carefully chosen from different segments of the study area that aim at hearing diverse perspectives about the issue that has been investigated. Hence, the sample was composed of eighteen experts, seven AE literacy centre coordinators, and seventy adult learners. A total of one hundred and five $(N=105)$ participants were drawn by using purposive and available sampling techniques. Data were obtained from all these respondents through multiple data-gathering instruments such as interviews, FGD, and document analysis. Besides, a semistructured interview was administered for AE experts and coordinators. The key interview issues were defined and arranged in the form of an interview guideline which helps to guide the focus as well as the direction of discussion with the interviewees. In line with the research basic questions and objectives that this study envisioned to address, the interview discussion topics were premeditated and semistructured into two broad categories. These are the integration of IK systems and practices into (a) the AE learning material development process and (b) utilization of the facilitation methodology. To get an in-depth understanding of the issues, other subthemes emerged during the discussions. In addition to this, FGD was carried out as a major data capturing strategy for adult learners. Participants in 
each focus group were confined to ten adult learners. Additionally, documented data related to $\mathrm{AE}$ and IK were obtained to relate and complement the data.

Procedurally, the discussion with each interviewee and focus group lasted between 45 and 60 minutes. Respondents' opinion was captured through audio recording and transcript verbatim. During gathering data and reporting, all respondents' confidentiality was protected using anonymity codes which represent study participants indirectly. Their name was coded; for instance, AE experts were pronounced as E1, E2, .... E8; AE coordinators were pronounced as C1, $\mathrm{C} 2, \ldots . \mathrm{C} 7$, and adult learners' opinion in FGDs was pronounced as FGD1, FGD2, ...... FGD8.

It is claimed that disclosing the methods of analysis with enough detail can enable the reader to determine whether the process is credible [42]. Hence, thematic analysis $[39,41,42]$ was employed as a major technique for analysing the data and interpreting the results of this study. In doing so, the collected data were considered through coding and a detailed description of the case under theme using ATLAS.ti 7. Then, a thorough explanation of the prevailing case events emerged parallel to this study data collection process. After the description, the researcher gave thoughtful attention to a few problems for investigation of the complexity of the cases. Finally, as suggested in [41], issues were identified within each case and then common themes that were established were looked for.

\section{Result}

Adult learning, material development, and utilization of cultural relevant facilitation methods have priceless value in promoting and transferring IK from generation to generation. This demands proper practice which emphasizes the integration of IK systems and practices into AE learning, material development, and facilitation mythology. The study uncovered how the practice has been carried out in NW. In doing so, the findings were presented in six subthemes categorised under two major themes as learning material development and facilitation methodology. The details are displayed below.

\subsection{The Integration of IK into Learning Material Development}

4.1.1. Considering Learners' Learning Needs and Their Experiences. The specific community has accumulated knowledge regarding widespread healing practices, wisdom on identification and classification of medicine and its mode of preparation, spiritual and philosophical aspects of folk medicine [43, 44], agricultural practice [45-47], reconciliation systems [14, 48, 49], traditional knowledge of construction [9], etc. Hence, preparation for learning material development must start with screening what kinds of knowledge systems and practices the individual and the community have. Before designing and developing IK-based AE learning materials, the following immense issues must be considered. These are (a) identifying who are the target beneficiaries, (b) dealing with who is responsible for what tasks, (c) what knowledge gaps are existing between what learners currently have and what they need to know, and (d) forecasting what learning outcome is expected to fill the existing knowledge gap. All these activities also call for the foundation of conducting a need assessment before starting to design and develop adult learning materials.

With this in mind, however, a discussion with adult learners (FGD2 and FGD3) and NW education department $\mathrm{AE}$ experts (E1) uncovered that learning material developers did not first comprehend and recognize what kinds of knowledge and experience learners have which could be integrated into AE programs. Correspondingly, meeting with FGD8, one participant exposed "the developed learning materials did not address many learning needs at a given point in time due to inadequate consideration of the learners' learning needs." This problem occurs in which entertaining all identified learning needs at a time becomes challenging due to resource constraints such as available time to program, availability of knowledgeable and skilful facilitators, and more extremely, lack of competent learning material developers in the area (E8). The results showed poor emphasis is given to exploring and understanding the indigenous perspectives of adult learners because of the mentioned constraints. If this practice continues, the implementation will be in serious trouble. That is why scholars in their previous study confirmed that one of the reasons for the low participation of adults in AE programs is due to the learning material development process that ignores the needs and interests of different groups [23].

\subsubsection{Considering Diverse Target Groups and Local Contexts.} As Yared et al. [17] suggested, when designing and implementing learning materials, the cultural capital learners bring from different places should be utilized and the interest, experience, economic class, and backgrounds of students should be considered. As part of the design process, developers ought to contemplate the expected teachinglearning styles, the facilitation methods to use, the time allocated for each of the learning objectives, methods employed for assessing participant learning, and the overall role of the material in the training effort. All these tasks must portray the multipart of IK values and beliefs, ceremonies, healing practices, social practices or institutions, and social organization which is displayed in a broad AE learning material. This helps to capture the accurate learning needs of beneficiaries for integration.

On the other hand, an interview with different district $\mathrm{AE}$ experts (E2, E3, E5, and E8) and discussions with adult learners (e.g., FGD2, FGD6, and FGD7) remarked that most of the time adult learning materials are not interactive and reinforced. This, in turn, makes adult learners frustrated to practice their prior know-how and establish new IK as well as skills. The observed fact tells two main areas of concern. The first one is considering learner-oriented learning material development that stands for learners to express the needs of their locality. Secondly, the need for improving learning materials frequently indigenizes and motivating learners regardless of their diverse learning needs. If these activities are addressed boldly, then the materials can be 
considered as a foundational benchmark for the inclusion of IK into AE programs. As a result, adult learners look to their social, cultural, and economic experiences as a base for their learning.

\subsubsection{Towards the Inclusion of Learners' Learning Culture} into AE Learning Materials. It is emphasized by previous studies the need for an educational system that incorporates learning methods and content inspired by ethnocentric thinking to fit the collectivist worldviews of the local context [17]. It is a fact that the cultural components of IK-based teaching and learning are strengthened in learning materials to gain a deeper understanding of other cultures. This demands a sound learning environment that entertains learners' culture irrespective of their differences in gender, racial background, religion, and others. From an interview with C3, C5, and E1 and the analysis of existing learning material, it was observed that the learning materials did not discriminate and discourage participants based on their differences. However, it lacks enough consideration of learners' learning culture. Knowing others is important in $\mathrm{AE}$ because it is the root for IK to be growing and conveying for other generations.

To enhance the positive inclusion of IK in adult learning, the learning material and its environment should be conducive to learning and adequately be portraited when designing it. This demands the facilitators' role of taking measures to ensure that the psychological (learners feel comfortable in their minds when they learn), physical (learning classes, chairs, buildings, etc.), and social environment (relationships, communication, understanding of others cultural perspectives, etc.) are safe, comfortable, and enjoyable for learning/facilitation.

\subsection{Facilitation Methodology Development and Utilization}

4.2.1. Getting Adult Learners Know. The community is the most important entry point to start our work. Indigenous beliefs, values, language, religion, culture, and occupations have their influence on how learning occurs. Hence, at the beginning of a nonformal education program facilitation, an educator/facilitator must know something about nature, its characteristics, and its people of the community to get their support of learning activities. Interview to AE coordinators (C1, C3, and C7) and discussion to FGD8 participants assured that, in different parts of the NW zone, numerous IK systems and practices such as traditional conflict management, local ways of saving and loans, small-scale farming, traditional construction systems, art and sculpture, and others exist in the community. Additionally, other respondents added that some individuals, i.e., adults, have "specialized knowledge" that can be used as a resource for learning. Even though it is expected that educators/facilitators firstly have sound know-how before facilitation start, the practice on the ground is far from proposed. They are selected for the facilitation jobs when they fail to achieve a university/college pass mark. Most of the AE facilitators are grade ten and twelve completers. The government and $\mathrm{AE}$ providers directly assigned them for facilitation mostly without adequate training about the nature of adult learning and learners (E2).

Adult learners have diverse learning needs, and they are coming to literacy centres of their own accord to empower themselves without anybody's enforcement. The abovementioned facts imply that building facilitators' knowledge of these will enhance asset-based learning evolving from local knowledge. This could be heightened through employing preservice and in-service continuous professional development actions for facilitators.

The learning contents and environments around them are, therefore, carefully designed in a manner to transform their personal, economic, and sociopolitical lives [26]. This means AE must accommodate such context-specific diverse needs because they have their positive value for integrating IK into programs. However, due to facilitators' lack of knowledge and skills about the andragogical principles of adult learning, their capacity to understand the indigenous learning and experience of adults, influence adult learners to be there in the AE program, and take part in an appropriate facilitation method properly (FGD8, C2, C4, and C5) is affected. As explained by Samuel and Abebaw [23], this, in turn, resulted in the low number of adult learners' participation in different learning centres. Indeed, when intended to use any learning activities, it must be integrated with what the communities/learners have and what they need. Facilitators must consider the indigenous community as an important resource for learning because they have their knowledge which will serve as a foundation for their learning.

4.2.2. Towards Context-Based Cooperative Learning. To be effective and relevant, education systems should fit the learners' worldview of the particular context [17]. In the observed area, one of the participants in the group discussion patriated the existence of a gap in integrating context-based learning contents and knowledge systems into AE practice. Furthermore, he thought that we come to this learning centre for different reasons. A few individuals have a special skill of reconciliation and resolving conflicts in my locality than any legal expert. Other people who have traditional knowledge to treat eye and ear ailments are also available in our village. They are accepted and respected by the local community due to their positive influence. I also have the practical skill of producing traditional farming equipment, for example, ploughs and yokes. Unless the owners share through these kinds of learning programs, the large majority of community members have not used these kinds of knowledge. We require our facilitators to let us learn together (FGD2).

However, other participants remarked on the deficiency of using individuals who have IKs as a base for the facilitation of AE provision.

We come here to the literacy/learning centre to gain and exchange knowledge each other use for our future. However, our facilitators teach us about other learning contents which are not our immediate learning needs. Considering and 
creating opportunities for sharing IKs and skills in adult and/or community education has been forgotten. Unfortunately, individuals who have IK are getting aged. One day, they may pass away and leave us. Unless the facilitators facilitate our learning cooperatively, how can we get such IKs from owners and experienced individuals? Also, what kinds of transferring this knowledge are there? There is nothing else. This issue must be highlighted by the concerned (FGD5).

These perspectives indicated the availability of shortcomings. Segregation of existing knowledge and team learning are the observed problems. To minimize the mentioned deficiency, learning material developers and facilitators have to organize the indigenous aspects of learning contents and must propose learners help each other during their learning. All adult learners have had many different experiences in their life based on past learning, everyday community life, and working. Every adult has a rich and full of experience that can be used to help to learn. As a result, educators can encourage individuals who have local knowledge about specific circumstances to benefit others. Using learners' typical experiences and skills through implementing peer learning and cooperative learning has meaningful standing for addressing such problems. As pronounced by scholars in the field, it is important to enhance learner-oriented learning content interactions in which learners examine, consider, and process together the learning information presented during the educational experience $[26,50]$. Moreover, the previous study suggested that cooperative learning could have priceless value to create an opportunity for learners from different experiences to work together and acquire competencies for social sustainability [17].

4.2.3. Using Influential Learners As a Potential to Fill the Existing AE Facilitation Gaps. As pointed out by the authors, generating opportunities for adult learners to use the learning time, explore their environment by interacting with each other, and make sense of their indigenous learning contents and experiences is critical to developing sustainable learning competencies [17]. That is why the process of $\mathrm{AE}$ facilitation is more shaped through guidance since each learner is mature in at least a specific learning experience [26]. Since adult learners have diverse learning experiences in which want to fill their immediate needs, facilitators during adult teaching-learning ought to perform the three expected tasks. These are (1) identifying participants' experience and their subsequent learning needs; (2) developing training concepts and learning objectives, and (3) applying appropriate facilitation methods by allowing the participation of the influential. Unfortunately, these practices were neglected because of facilitators' absence of ability towards how to use learners as a resource of learning. Besides, one participant of this study emphasized that look my brother, our literacy program facilitator looks for the support of the local people to encourage learners' participation in the $\mathrm{AE}$ program. However, she is frustrated to mobilize especially individuals who have IK than others. This practice contributes to the existence of an observable gap in connecting elders with young learners; in other words, there is the deficiency of connecting individuals who know the specific area with others and delivering IK-based learning content. For instance, individuals who have experience in different fields such as knowledge of traditional medicine, religious healing, and best practice in small-scale farming have not been considered resource people in these learning programs. As a result, integrating these kinds of local knowledge into $\mathrm{AE}$ is found far from what we proposed (FGD6).

This kind of facilitation gap can be solved if facilitators use influential individuals, voluntary groups, local leaders, privileged ethnic individuals, and religious fathers within the community as a means of mobilizing community learning. Moreover, adult learners' experiences from diverse perspectives are an asset that needs to be utilized in sustainability education. Hence, capitalizing on learners' IK complements and contextualizes the current facilitation gaps that existed in provision of AE. As such, experienced learners become active contributors to adult learning and their level of engagement is taken to a higher level in the process of fostering their sustainability competencies [17]. This may be carried out by promoting learners' active participation in their learning experience and inviting them to decide on the content, skills, and knowledge that will be covered by whom. In doing so, not only the AE curriculum but also the facilitation practice must be reestablished in time to promote a realistic and positive inclusion of the IK into the learning materials and training.

\section{Discussion}

Indigenous-based education is multifunctional in any society, so it ensures continuity of life; as individuals in society get old and die, a new generation is born that needs to be inculcated with the values, morals, culture, and way of life of society [12]. It is also suggested that IK offers rich and authentic contexts for learning and provides chances to reflect views on nature and science in contemporary education [10]. These operationalized meanings (IK and education) call for integration contributing to the establishment of well-adjusted and all-inclusive worldviews, intercultural thought, and sustainability. At this time, this study finding showed that the provision of $\mathrm{AE}$ is disconnected from IK in the NW zone. The AE learning contents and experience in material development and facilitation methods have not been adequately localized. Unless concerned redress this practice, similar studies showed that alternative worldviews and ways of knowing about the realm of IK through local ways of knowing such as traditions, customs, and practices will continue as the evolving gaps $[17,33]$. On the other hand, Yared et al. [17] in their study suggested four possible ways to integrate IK systems and practice into AE. The first is to define local worldviews, the education system and the worldview should be based on participant history or culture. Secondly, local content and examples should be portraited; when teaching, the use of relevant real-world local applications can make learning more indigenized and effective. 
Thirdly, apprenticeship opportunities in the local environment take advantage of using local expertise. Fourthly, inviting guest lecturers, people with IK should be included to teach parts of the course where their expertise is relevant. This helps learners to gain practical experience and makes learning more meaningful for them.

Furthermore, this study result uncovered the presence of AE learning material limitations on (1) understanding and recognizing what kinds of IK and experiences are available to be integrated into the program and (2) the developed adult learning materials are not interactive and reinforced. The materials help learners not only develop new knowledge, skills, and experiences but also strengthen the existing ones which are extracted from their indigenous perspectives. This, in turn, makes adult learners frustrated to practice their prior know-how and establish new IK in their learning. In the body of literature, it has been known that the process of learning material design requires integrating learners' prior knowledge that they bring from home and using aspects of this knowledge as the starting point for enabling learners to understand the technical concepts described in curriculumbased textbooks [51]. Therefore, the design and arrangement of indigenous-based learning should include the development, implementation, and reflection of adult learners' experiences through developing context-specific learning materials, styles, and principles [10].

As scholars argued, IK-based adult learning can help learners recognize their intimate connection with nature in the foreground of values from their environment or beyond [10] because education can also act as a change agent in society. Therefore, the learning materials must be shaped in a manner to constantly question the knowledge that learners bring experiential knowledge in the form of specific practices which may contribute to learning to be more interactive [51]. More specifically, a review of studies conducted by Karalis and Vorvilas [50] about AE learning material design showed that a good self-instructional material has some peculiar features which make it prominent. According to them, (1) it is oriented to individual learners and self-paced learning structured according to learners' needs, (2) it is available at any time and any place to any number of learners considering the context, (3) it is articulated in a standardized, expert, and updatable learning content and experience with explicit aims, objectives, and feedback, and (4) it promotes structured teaching and individualized tutoring. Hence, adopting such kinds of strategies significantly helps to minimize the existing gaps in learning material design.

Regarding the utilization of AE facilitation methods, this study pointed out that facilitators' deficiency of knowledge and skills about the andragogical principles of adult learning desperately affects (1) their capacity to understand the indigenous experience of adults and their learning needs and (2) proper utilization of the facilitation method. It appears that there is a knowledge gap about integrating contextbased indigenous learning contents and the needed facilitation systems in AE practice. This kind of problem is minimized when the concerned bodies empower AE facilitators. As discussed by Araújo et al. [52] and Karalis and Vorvilas [50], each collaborator such as AE learning materials, developers, and respective education professional associations, therefore, needs to take into consideration the wide-ranging knowledge about (a) the background of the learners and their experience and knowledge; (b) the nature of $\mathrm{AE}$ and its main objectives; (c) what indigenous learning contents adults want to learn and where they want to learn; and (d) the desirable responsive facilitation methodology. Literature showed that the development of AE curriculum, learning materials, and facilitation styles without a clear understanding of the needs and expectations of the adult learner created a huge void [23]. Therefore, in AE, facilitators need to enhance learners' meaningful engagement through employing learner-oriented facilitation methods and limiting their role in controlling the learning process $[17,26]$. Likewise, local knowledge systems are credible possibilities and their use needs to be enhanced during learning to promote people's adaptive potential to a multitude of troubles [45]. In this sense, types of place-based learning are required to integrate the local knowledge systems into the AE curriculum. For instance, Yared et al. [17] suggested indigenous-based discussion, place-based learning, and field trips as a means of facilitating adult learning because these approaches give learners real-world experience and the opportunity for meaningful engagement.

The incorporation and promotion of IK into learning materials through the utilization of proper facilitation methods can help to enable adult learners to gain positive experiences and develop corresponding attitudes towards their learning without any difference [10]. Similarly, this study finding confirmed that the process did not discriminate and discourage participants regardless of their differences. However, the facilitation lacks enough consideration of adult learners' learning principles. This may be the fact that the rationality of the used methodology can be influenced by the inadequate arrangement of its content and learner understanding level which demand contextualized facilitation methods [50]. Hence, as agreed by scholars, considering local social practices since they affect learners is important in integrating IK into AE programs teaching/ facilitation methods $[23,50]$.

The community has its own culture in which IK is originated. In many areas, traditional IK is characterized by confidentiality and restricted diffusion of knowledge outside of their family, which may result in the gradual erosion of IK [43]. This culture hurts transferring IK to others through learning platforms unless significant work has been carried out. When including indigenous culture and knowledge in learning, communities' social values such as philosophy, tradition, and beliefs are enhanced. On the contrary, when cultural practice has minimized, the community members become troubled. Even though the owners of IK may be small in number, using the full effort to connect them to $\mathrm{AE}$ has a priceless worth for the sustainability of IK in $\mathrm{AE}$ program provision. Unfortunately, this study pointed out the role played by $\mathrm{AE}$ facilitators using influential individuals, voluntary groups, local leaders, privileged ethnic individuals, and religious fathers as a means of mobilizing community learning and integrating the available IK learning contents and experiences found in the ground. This 
finding was also congruent with the earlier study findings that revealed a lack of an interdisciplinary approach, which was described as a barrier for the effective model for adults to learn from each other [23]. In this sense, therefore, $\mathrm{AE}$ facilitators' developing content knowledge alone is not enough to provide training for adult learners. It also requires understanding what other partners could contribute to the effective indigenization of $\mathrm{AE}$ facilitation.

\section{Conclusions}

Adult learners' IK and experiences from diverse perspectives are an asset that needs to be utilized in sustainability education. Hence, connecting IK systems and practices with AE programs have priceless value of promoting and transferring IK from generation to generation. This demands the development of relevant learning materials and the utilization of responsive facilitation methodologies. With this in mind, therefore, this study found it is possible to conclude that even though adult learners have diverse learning experiences, narrow emphasis has been given to the development of learning concepts and objectives in learning materials and the application of appropriate facilitation methods through participating experienced learners. Hence, taking advantage of learners' IK accompaniment helps the current practice gaps that exist in the provisions of AE programs. This may be carried out by encouraging learners' vigorous contribution to their learning and inviting them to decide on the content, skills, and knowledge that will be covered by whom and how. In doing so, not only AE learning materials must be reestablished in time to promote a realistic and positive inclusion of the IK but also facilitators should employ cooperative and team learning methods during the training.

\section{Suggestions for Future Studies}

The nature of IK and AE is so broad and studying it to such an extent requires a large time, many numbers of researchers, and resources. With these constraints in mind, the researcher delimited the study to discourse the development of $\mathrm{AE}$ learning materials and facilitation methodology across learners' indigenous perspectives, knowledge, experience, and cultural contexts. Due to this, other issues related to IK and AE practice were not considered in this study. Subsequently, the researcher suggested academic scholars, research institutions, and all concerned actors exploring and discoursing the following issues. First, the integration of IK into AE practice has been practiced fully of many ups and downs. Therefore, academicians and researchers are suggested to scrutinize practical challenges, available opportunities, and contextual considerations of IK and AE. Second, the implementation of indigenous-based $\mathrm{AE}$ has been seen by some stakeholders as their secondary task despite it demanding a collective effort. Hence, exploring the established intersectoral collaboration towards integrating IK into $\mathrm{AE}$ is needed.

\section{Data Availability}

Data are available from the author on a reasonable request.

\section{Conflicts of Interest}

The author declares no conflicts of interest.

\section{References}

[1] J. Hamilton-Ekeke and E. Dorgu, "Curriculum and indigenous education for technological advancement," British Journal of Education, vol. 3, no. 11, pp. 32-39, 2015.

[2] T. Abera, "Indigenous knowledge for sustainability education in Ethiopia," IMPACT: International Journal of Research in Humanities, Arts and Literature, vol. 8, no. 1, pp. 39-48, 2020.

[3] J. Austin and A. Hickey, "Incorporating indigenous knowledge into the curriculum: responses of science teacher educators," The International Journal of Science in Society, vol. 2, no. 4, pp. 139-152, 2011.

[4] M. Bag, "Industrialization: a threat to the indigenous knowledge of ethno-medicine," ACME Intellects International Journal of Research in Management, Social Science \& Technology, vol. 20, no. 20, pp. 1-13, 2017.

[5] G. Emeagwali and G. J. S. Dei, "African indigenous knowledge and the disciplines," in African Indigenous Knowledge and the Disciplines, Sense Publishers, Rotterdam, The Netherlands, 2014.

[6] K. Adom, "Indigenous knowledge for environmental sustainability education in Ghana: Myths," Agriculture \& Food: E-Newsletter, vol. 1, no. 3, pp. 43-45, 2019.

[7] S. Singh and A. Saha, "Documentation of indigenous knowledge in the farming system," International Journal of Bio-Resource, Environment and Agricultural Sciences (IJBEAS), vol. 3, no. 2, pp. 548-553, 2017.

[8] S. Lodhi and I. Naseem, "Systems thinking," Introduction to Knowledge Management, vol. 4, no. 9, pp. 83-92, 2012.

[9] M. Robso, "Where indigenous knowledge is beyond modernity: an experience from the Ethiopian orthodox Church traditional adult education practices, Ethiopia," Palarch's Journal of Archaeology of Egypt/Egyptology, vol. 18, no. 1, pp. 4143-4160, 2021.

[10] R. Zidny, J. Sjöström, and I. Eilks, "A multi-perspective reflection on how indigenous knowledge and related ideas can Improve science education for sustainability," Science \& Education, vol. 29, no. 1, pp. 145-185, 2020.

[11] T. E. Lukong, "Indigenous peoples education: priorities for inclusive education, the case of Cameroon," International Journal of History and Cultural Studies, vol. 2, no. 3, pp. 17-27, 2016.

[12] C. Ezeanya-Esiobu, "Indigenous knowledge and education in Africa," in Indigenous Knowledge and Education in Africa, Springer Nature Pte Ltd, Berlin, Germany, 2019.

[13] S. L. Morrison, T. Vaioleti, and N. G. D’Souza, Quality Adult Education Benchmarks for Indigenous Education, Asia South Pacific Association for Basic and Adult Education (ASPBAE), Quezon City, Philippines, 2011.

[14] M. Yigzaw and M.-C. Boudreau, "Indigenous knowledge creation practices: the case of Ethiopia," in Proceedings of the 18th European Conference on Information Systems, Pretoria, South Africa, June 2010.

[15] W. Ferede, "Indigenizing the educational system of Ethiopia," Proceedings of the $8^{\text {th }}$ Multi-Disciplinary Seminar, vol. 8, pp. 78-84, 2005. 
[16] W. Kebede and S. Belay, "The nexus between culture, indigenous knowledge and development in Ethiopia: review of existing literature," Global Journal of Human-Social Science: $C$ Sociology \& Culture, vol. 17, no. 4, pp. 1-9, 2017.

[17] N. Yared, H. J. A. Biemans, R. Wesselink, and M. Martin, "Combining indigenous knowledge and modern education to foster sustainability competencies: towards a set of learning design principles," Sustainability, vol. 12, no. 6823, pp. 1-20, 2020.

[18] M. Abiy, A. Roger, and Z. Turuwark, "Leaving the job half done? an analysis of mid-term withdrawals by facilitators in some adult literacy learning programs," International Journal of Educational Development, vol. 65, pp. 194-206, 2019.

[19] K. Ambissa, "Adult basic literacy "initiatives" in Ethiopia: change and continuity," Journal for Critical Education Policy Studies, vol. 12, no. 1, pp. 238-261, 2014.

[20] W. Dessu, "Provision and participants of adult education: an overview," Adult Education and Development, vol. 22, no. 1, pp. 196-210, 2005.

[21] G. Genet, “An assessment of Ethiopia's progress towards attaining integrated functional adult literacy," Bahir Dar Journal of Education, vol. 14, no. 2, pp. 14-28, 2014.

[22] D. Samuel, G. Gelana, and D. Mekonnen, "Developing a lifelong learning system in Ethiopia: contextual considerations and propositions," International Review of Education, vol. 60, no. 5, pp. 639-660, 2014.

[23] G. Samuel and Y. Abebaw, "Factors affecting intersectoral collaboration in the provision of adult education in Ethiopia," Studies in the Education of Adults, vol. 53, no. 1, pp. 42-60, 2021.

[24] B. Sandhaas, Portrait Adult Education Ethiopia, DVV International, Bonn, Germany, 2009.

[25] Z. Turuwark, A. Rogers, and N. Tolera, "Profiling adult literacy facilitators in development contexts: an ethnographic study in Ethiopia," International Review of Education, vol. 64, no. 1, pp. 9-30, 2018.

[26] A. Yalalem, "Towards learner-oriented monitoring and evaluation in adult education program: a vital approach to ensure adult learners' learning needs," Education Research International, vol. 2021, Article ID 6663700, 11 pages, 2021.

[27] G. Japee and P. Oza, "Curriculum and evaluation in outcomebased education," Psychology and Education Journal, vol. 58, no. 2, pp. 5620-5625, 2021.

[28] F. Murillo, "The curriculum of the plague," Prospects, vol. 2021, pp. 1-12, 2021.

[29] A. Gultom, A. Natasha, H. K. Mardiyah, S. V. Ain, and R. R. Wandini, "The rationalization of curriculum development," Jurnal Tarbiyah, vol. 27, no. 2, pp. 1-13, 2020.

[30] T. C. Werler and A. Tahirsylaj, "Differences in teacher education programmes and their outcomes across Didaktik and curriculum traditions," European Journal of Teacher Education, vol. 43, pp. 1-19, 2020.

[31] D. Hodson, "Going beyond STS education: building a curriculum for sociopolitical activism," Canadian Journal of Science, Mathematics and Technology Education, vol. 20, no. 4, pp. 592-622, 2021.

[32] V. Van Bewer, R. L. Woodgate, D. Martin, and F. Deer, "The importance and promise of integrating Indigenous knowledges in nursing education," Witness: The Canadian Journal of Critical Nursing Discourse, vol. 2, no. 1, pp. 11-24, 2020.

[33] M. Mawere, "Indigenous knowledge and public education in Sub-Saharan Africa," Africa Spectrum, vol. 50, no. 2, pp. 57-71, 2015.
[34] C. Rogers-Shaw, D. J. Carr-Chellman, and J. Choi, "Universal design for learning: guidelines for accessible online instruction," Adult Learning, vol. 29, no. 2, pp. 1-12, 2018.

[35] P. Yeoman and L. Carvalho, "Moving between material and conceptual structure: developing a card-based method to support design for learning," Design Studies, vol. 64, pp. 6489, 2019.

[36] V. Anthony-Stevens, J. Jones, and V. Begay, "Regenerating teacher education programs with indigenous knowledge in Idaho," Northwest Journal of Teacher Education, vol. 15, no. 3, pp. 1-12, 2020.

[37] B. A. Naamwintome and D. Millar, "Indigenous knowledge and the African way forward: challenges and opportunities," OALib, vol. 2, no. e1295, pp. 1-9, 2015.

[38] S. Carter, D. Laurs, L. Chant, and E. Wolfgramm-Foliaki, "Indigenous knowledges and supervision: changing the lens," Innovations in Education and Teaching International, vol. 55, no. 3, pp. 384-393, 2018.

[39] L. Cohen, L. Manion, and K. R. B. Morrison, Research Methods in Education, Routledge, Abingdon, England, 6th edition, 2007.

[40] R. Kumar, Research Methodology a Step-by-Step Guide for Beginners, SAGE Publications, Thousand Oaks, CA, USA, 2011, http://library1.nida.ac.th/termpaper6/sd/2554/19755. pdf.

[41] J. Creswell, Research Design: Qualitative, Quantitative, and Mixed Methods Approach, SAGE Publications, Thousand Oaks, CA, USA, 2018, http://library1.nida.ac.th/termpaper6/ sd/2554/19755.pdf.

[42] L. S. Nowell, J. M. Norris, D. E. White, and N. J. Moules, "Thematic analysis: striving to meet the trustworthiness criteria," International Journal of Qualitative Methods, vol. 16, no. 1, pp. 1-13, 2017.

[43] G. Gonfa and D. Wirtu, "Ethnomedical knowledge and indigenous healthcare practices in Nekemte District, Western Ethiopia: a qualitative study," Ethiopian Journal of Health Development, vol. 33, no. 1, pp. 17-21, 2019.

[44] M. Tufa and F. M. Gebremariam, "The role of indigenous healing practices in environmental protection among the maccaa oromo of Ilu Abbaa," Social Sciences and Education Research Review, vol. 4, no. 1, pp. 30-53, 2017.

[45] M. Asmamaw, T. Seid, and A. Ambelu, "The role of local knowledge in enhancing the resilience of dinki watershed social-ecological system, central highlands of," PLoS One, vol. 15, no. 9, pp. 1-18, 2020.

[46] B. Baye and W. Teshome, "The role indigenous knowledge in agricultural farming practices: the case of Gonder and Gojam area, Amhara regional state, Ethiopia," International Journal of Advanced Research in Biological Sciences, vol. 7, no. 12, pp. 106-112, 2020.

[47] M. Temesgen, B. Tesfaye, M. Catellani, and M. E. Pè, "Indigenous knowledge, use and on-farm management of enset (Ensete ventricosum (Welw.) Cheesman) diversity in Wolaita, Southern Ethiopia," Journal of Ethnobiology and Ethnomedicine, vol. 10, no. 41, pp. 1-18, 2014.

[48] A. Ajanaw and M. Hone, "Reaching harmony across indigenous and mainstream contexts: an emergent narrative," Journal of Indigenous Social Development, vol. 7, no. 2, pp. 1-21, 2018.

[49] D. Nakashima and R. Marie, "Indigenous knowledge, peoples and sustainable practice," Social and Economic Dimensions of Global Environmental Change, vol. 5, pp. 314-324, 2002.

[50] T. Karalis and G. Vorvilas, "Designing multimedia learning material for adult education: an interdisciplinary approach," 
Review of Science, Mathematics and ICT Education, vol. 5, no. 2, pp. 85-108, 2011.

[51] C. Mandikonza, "Integrating indigenous knowledge practices as context and concepts for the learning of curriculum science: a methodological exploration," Southern African Journal of Environmental Education, vol. 35, no. 1, pp. 254-257, 2019.

[52] R. A. Araújo, J. M. D. M. Zanatta, J. C. André et al., "Active teaching-learning methodologies in an undergraduate course of medicine with a traditional curriculum," International Journal for Innovation Education and Research, vol. 8, no. 6, pp. 532-544, 2020. 